\title{
APPROXIMATIONS USING HILBERT TRANSFORM OF WAVELETS
}

\author{
NikHil Khanna, VARINDER Kumar And S. K. KAUshiK
}

Abstract. Hilbert transform of wavelets has been used to approximate functions in $L^{2}(\mathbb{R})$. It is proved that Hilbert transform of wavelets with many vanishing moments does a good job in approximating smooth functions in $L^{2}(\mathbb{R})$. We also prove that Hölder continuity of a function helps in the decay of wavelet coefficients and thereby helps in approximating it. Finally, we give a result that relates the Hilbert transform of wavelet with dyadic scale differential operator and use it to decrease the wavelet coefficients.

Mathematics subject classification (2010): 44A15, 42A38, 65T60, 41A35.

Keywords and phrases: Hilbert transform, Fourier transform, wavelets, approximation.

\section{REFERENCES}

[1] J. CEA, Approximation variationnelle des problèmes aux limites, Annales de l'institut Fourier 14 (2), (1964), 345-444.

[2] K. N. Chaudhary And M. Unser, On the Hilbert Transform of Wavelets, IEEE Transactions on Signal Processing, 59 (4), (2011), 1890-1894.

[3] L. Debnath And D. BhatTA, Integral Transforms and Their Applications (Second Edition), CRC Press, Boca Raton, Florida, 2006.

[4] M. Holschneider and Ph. TChamitchian, Pointwise analysis of Riemann's "nondifferentiable" function, Invent. math. 105, (1991), 157-175.

[5] A. M. Jarrah AND S. PANWAR, On Hilbert Transform of Gabor and Wilson Systems, International Journal of Wavelets, Multiresolution and Information Processing, World Scientific, 12 (2), (2014), 1450012/1-1450012/9.

[6] F. W. KIng, Hilbert Transforms, Vol. 1, Cambridge University Press, 2009.

[7] S. G. Mallat, A Wavelet Tour of Signal Processing, Academic Press, 1998.

[8] L. R. SoAres, H. M. de Oliveira, and R. J. S. Cintra, The Fourier-like and Hartley-like Wavelet Analysis Based on Hilbert Transforms, in Annals of the XXII Simpósio Brasileiro de Telecomunicaes (SBT’ 05), Campinas, Brazil, (2005), 4-8.

[9] D. F. WALnUT, An introduction to wavelet analysis, Boston, MA: Birkhäuser, 2002.

[10] A. Zygmund, Trigonometric Series, Vols. I, II, 2nd ed., Cambridge University Press, New York, 1959. 